\title{
Relationship between Pre-Cystoscopy Anxiety and Post-Cystoscopy Pain: A Cross Sectional Study
}

\author{
Abolfazl Amini ${ }^{1}$, Seyed Naser Seyed Esmaieli ${ }^{2}$, Ramin Bayat ${ }^{3}$, Mohammad Hosseinkhani ${ }^{4}$ \& Ali Ghaempanah ${ }^{1}$ \\ ${ }^{1}$ School of Nursing and Midwifery, Zanjan University of Medical Sciences, Zanjan, Iran \\ ${ }^{2}$ Fellowship of Endurology \& Urolaparoscopy, Department of Urology, School of Medicine, Tehran University \\ of Medical Science, Tehran, Iran \\ ${ }^{3}$ School of Nursing and Midwifery, Tehran University of Medical Sciences, Tehran, Iran \\ ${ }^{4}$ Surgical Technology, Department of Surgery, Amiralmomenin Hospital, Zanjan, Iran \\ Correspondence: Ramin Bayat, MScN, School of Nursing and Midwifery, Tehran University of Medical Sciences, \\ Tehran, Iran. Tel: 0098-91-9547-2976. E-mail: baiatramin@gmail.com
}

Received: May 7, 2020

Accepted: July 18, 2020

Online Published: November 30, 2020

doi:10.5539/jmbr.v10n1p131

URL: https://doi.org/10.5539/jmbr.v10n1p131

\begin{abstract}
Introduction: Cystoscopy is one of the common procedure in diagnosis and treatment of problem related to urinary tract, pre-cystoscopy anxiety is a very common problem, despite evidences shows suitable intervention for post-cystoscopy pain but enough pain relief still remains as a problem, the aim of this study was to investigate the relationship between pre-cystoscopy anxiety and post-cystoscopy pain among patients who was hospitalized for cystoscopy.

Methods: This was a cross sectional study and sampling of this study was done in April 2017 to April 2018 in surgical unit of amiralmoemenin hospital in zanjan, Iran, using non-probability convenience Sampling method, 61 patients aged 16-45 years old who was hospitalized for cystoscopy was recruited in this study. Pre-cystoscopy anxiety was assessed by spilberger (STAI) questionnaire and post-cystoscopy pain measured by pain visual analogs scale (VAS).

Results: The mean (SD) age of men and females were 43.81 (14.68), 44.88 (13.61) years old, respectively The relationship between state anxiety and post cystoscopy pain was direct and significant $(p<0.05)$. The relationship between trait anxiety and post cystoscopy pain was direct and significant too $(\mathrm{p}<0.05)$.

Conclusion: the state and trait Anxiety of patients who were hospitalized for cystoscopy could increases the intensity of patients' pain in post-cystoscopy.
\end{abstract}

Keywords: Anxiety, Pain, Cystoscopy, Cross-Sectional Studies

\section{Introduction}

Cystoscopy is an important diagnostic method over the past 150 years. Each person typically experiences cystoscopy throughout his life, but since it is main method for assessment and diagnosis bladder tumor, cystoscopy is more common in individuals with bladder tumors (Jellinghaus, 1979).

The main goal of cystoscopy is to evaluate the patients thoroughly and accurately, without discomfort and without using sedative medications. The success of cystoscopy depends on insertion of the instrument into the bladder, precise observation and minimize patient discomfort during the procedure, although Technical advancements have reduced pain and discomfort in cystoscopy, but several studies have demonstrated significant pain and discomfort in cystoscopy due to the procedure and environmental status (Burke, Shackley, \& O'reilly, 2002; Grossfeld et al., 2001). Recognition and treatment of pain is one of the oldest sciences which humans to find out more about it. From the beginning of creation, humans have suffered from pain and have achieved tremendous achievements in dealing with it. But pain is still one of the major problems in global health that people have been terrified throughout life, which may also be eradicated by pain (Nikbakht Nasrabadi, 1994). various ways have been used to pain relief (Bonica, 1990), Because effective pain treatment prevents the physiological and psychological harmful results of this phenomenon, the effective pain treatment is very considerable both in patient's recovery and in patient's economic condition (Chung, Hou, \& Pan, 2004).

Despite the evidences shows suitable intervention for post-operative pain, but the enough pain relief treatments 
still remains as a problem (Watt-Watson, Stevens, Garfinkel, Streiner, \& Gallop, 2001). Acute post-operative pain is one of the worse pain that human tolerates and this pain be more intense, it creates more unfavorable hemodynamic and metabolic responses (Dabbagh et al., 2010). Post-operative pain can cause to harmful results, for example: thromboembolism, reduce of myocardial perfusion, increase of surgical site infection, irregular heartbeat, Urinary retention, bowel obstruction, delay in wound healing, delay in return stomach movements, increase of nausea, severe inability, and delay in starting oral nutrition (Andaroodi, Mahoori, Abbasivash, Noroozinia, \& Heshmati, 2006; Mokhtari, Sirati, Sadeghi, Ghanbari, Babatabar, \& Mahmoudi, 2010).

One of the factors that may effect on patients' post-operative pain is rate of pre-operative anxiety (Kim, Byeon, Song, \& Lee, 2010). Studies showed that the patients are very agitated before surgery (Gunnarsdottir \& Jonsdottir, 2007). Cystoscopy can cause to anxiety in patients too (Morgan, Roufeil, Kaushik, \& Bassett, 1998).

Anxiety is a vague feeling, worry that often creates due to exposure to unfamiliar situations, the risk of death, fear, changes of body shape or function, increase of dependency, familial concerns and lifestyle acute changes (Zakerimoghadam, Aliasgharpoor, Mehran, \& Mohammadi, 2010). Pre-operative anxiety is a very common problem among hospitalized patients (Bassampour, Nikbakht Nasrabadi, Mehran, Poresmaeil, \& Valiee, 2008).

Boker et al. (2002) stated that the rate of pre-operative anxiety is 60 percent (Boker, Brownell, \& Donen, 2002) Pre-operative anxiety is a challenging aspect in pre-operative care, most patients who waiting for elective surgery are anxious and it widely accepted as an expected response (Badner, Nielson, Munk, Kwiatkowska, \& Gelb, 1990).

Studies showed that high level of pre-operative anxiety can lead to increase of post-operative analgesic demand, increase of hospitalization time, and reduce the patients' satisfactions (Hobson, Slade, Wrench, \& Power, 2006). Because anxiety effects on the patient's mental state and it may have an adverse effect on treatment outcomes, it is very important that nurses consider the strategies to increase comfort and reduce the stress and anxiety in patients (Gagner-Tjellesen, Yurkovich, \& Gragert, 2001).

In a study conducted by Stein et al. (1994) the anesthesia effect of intraurethral lidocaine gel and anxiety of patient on pain during cystoscopy was measured. In this study they found no decrease in pain perception in men or women following lidocaine gel instillation with a 5 or 10-minute dwell time compared to instillation of the plain lubricant. Increased pre procedure anxiety was correlated with increased pain perception in women. Personal experience with prior cystoscopy procedures significantly decreased the current pain perception in men (Stein, Lubetkin, Taub, Skinner, Haberman, \& Kreutzer, 1994).

Soomro et al. (2011) evaluated the effect of patient's self-viewing on cystoscopy's pain, so the samples viewed the cystoscopy's procedure on a video then the pain of patients was evaluated. The results showed that the patients who viewed the cystoscopy procedure on a video monitor, reported less pain on a visual analog scale than the control group (Soomro, Nasir, \& Ather, 2011).

Ganei et al. (2013) evaluated the relationship between pre-Caesarean anxieties with post-caesarean pain. The results showed pre-operative anxiety significantly was related to post-operative pain (Ganei, Rezai, \& Mohamady, 2013). According to this study, it can be concluded that there is likely a relationship between the pre-cystoscopy's anxieties and the post-cystoscopy's pain.

Yeo et al. (2013) in South Korea, evaluated the impact of music listening (one of anxiety reducing methods) for reducing anxiety, pain and dissatisfaction during cystoscopy, the results showed positive effect (Yeo, Cho, Oh, Park, \& Park, 2013).

Cystoscopy is one of common urologic surgery which pain is main problem in this method. Using analgesic drugs may cause Complications for patient. By regard that similar study didn't work in Iran and related studies that done in world have contradictory results about relationship between pre-cystoscopy's anxiety and postcystoscopy's pain. So the aim of present study was assessing the relationship between pre-cystoscopy's anxiety and post-cystoscopy's pain in patients who was hospitalized for cystoscopy in surgical unit of amiralmoemenin hospital in zanjan, Iran.

\section{Material \& Methods}

The sample size in this study was 61 patients, in this cross-sectional study; the sampling was done from April 2017 to April 2018 in surgical unit of amiralmomenin hospital in zanjan, Iran. Only 61 patients with inclusion criteria referred to surgical unit during that time so the research team was forced to end the study with this sample size. In this study, a non-probability convenience sampling method was used. This means that after attending the surgical unit, patients who had inclusion criteria of this study were enrolled to the study 
Table 1. Inclusion and exclusion criteria

\begin{tabular}{ll}
\hline Inclusion criteria & Exclusion criteria \\
\hline Consciousness & Performing concurrent surgery such as TUL, TURP... \\
Ability of reading and writing & Addiction to opium \\
The desire to participate in the study & Using anxiety and analgesic drugs \\
& Occurrence of post-surgical Complications such as bleeding \\
& Failure to complete the full questionnaire \\
\hline
\end{tabular}

The project proposal legislated with the ethics code (ZUMS.REC.1396.09) in Zanjan University of Medical Sciences. Then an introduction letter from Zanjan University of Medical Sciences was taken and referred to surgical unit of amiralmomenin hospital in Zanjan, Iran, for sampling and getting information of them This study was done in tree steps. First step; getting information about the goal of study and confidentiality of information was given to the samples, then the consent forms was taken from the patients and demographic characterizes of samples was recorded, second step; spillberger questionnaire (questionnaire for pre-cystoscopy's anxiety of patients) were completed by cystoscopic candidates before cystoscopy. third steps; secondary questionnaire (VAS; Visual Analogs Scale) for post-cystoscopy's pain were completed by them two hours after cystoscopy (Ganei, Rezai, \& Mohamady, 2013). The two questionnaires were given to 61 patients that had inclusions criteria, all of the patients completed questionnaires correctly and finally, 61 samples participate for final analysis.

Spilberger questionnaire (State-Trait Anxiety Inventory (STAI)): spilberger questionnaire was used for collecting information about state and trait anxiety, validity of this questionnaire was assessed in the study of rabiee's et al., by 10 experts nurses through expert panels (Rabiee \& Kazemi Malek Mahmodi, 2007), and reliability of this questionnaire was $86 \%$ (Alpha coefficients )that evaluated in Tiedeman's study (Tiedeman \& Clatworthy, 1990). This questionnaire has 40 items that 20 items assesses state anxiety and 20 items assesses trait anxiety.

Visual Analog Scale (VAS): Intensity of patient's pain has measured two hours after cystoscopy by The VAS. The validity of this instrument was done in several country like Iran (Mudgalkar, Bele, Valsangkar, Bodhare, \& Gorre, 2012; Fadaizadeh, Emami, \& Samii, 2009), also the reliability of this instrument has been performed widely (Bijur, Silver, \& Gallagher, 2001). The VAS is a 10 - CM vertical or horizontal line with anchors of no pain on one end and worst pain on the other (Gift, 1989).

For data analysis, the SPSS $_{21}$ (Chicago, IL, USA) was used .To determine the normal distribution of data, the Kolmogorov-Smirnov test (K-S) was used. Spearman correlation test was used to measure the relationship between pre-cystoscopy's anxiety and post- cystoscopy's pain.

\section{Results}

The mean (SD) age of men and females were 43.81(14.68), 44.88(13.61) years old, respectively. other demographic characters has been given in Table 2 .

Table 2. Demographic Characteristic of qualitative variables

\begin{tabular}{|c|c|c|c|}
\hline & & Frequency & Percent (100\%) \\
\hline \multirow{2}{*}{ Gender } & male & 44 & 72.1 \\
\hline & female & 17 & 27.9 \\
\hline \multirow{2}{*}{ Marital status } & Married & 48 & 78.7 \\
\hline & single & 13 & 21.3 \\
\hline \multirow{2}{*}{ Living area } & urban & 21 & 34.4 \\
\hline & village & 40 & 65.6 \\
\hline \multirow{2}{*}{ Surgical history } & Yes & 38 & 62.3 \\
\hline & No & 23 & 37.7 \\
\hline \multirow{4}{*}{ Educational level } & illiterate & 32 & 52.5 \\
\hline & middle school degree & 10 & 16.1 \\
\hline & High school diploma & 9 & 14.8 \\
\hline & Upper High school diploma & 10 & 16.4 \\
\hline \multirow{3}{*}{ Job } & Unemployed & 19 & 31.1 \\
\hline & Employee & 8 & 13.1 \\
\hline & Self-employed & 34 & 55.7 \\
\hline
\end{tabular}


The distribution of data was not normal $(P<0.05)$. Therefore, the spearman test was used for analyzing the relationship between variables. The results of analysis of the relationship between patients' state and trait anxiety with post-cystoscopy's pain are given in Table 3. There was direct and significant relationship between patients' state anxiety with post-cystoscopy's pain $(\mathrm{p}=0.005)$. There was direct and significant relationship between patients' trait anxiety with post-cystoscopy's pain $(\mathrm{p}=0.025)$ and there was direct and significant relationship between patients' state and trait anxiety too $(\mathrm{P}=0.000)$.

Table 3. Relationship between patients' state and trait anxiety with post-cystoscopy pain

\begin{tabular}{|c|c|c|c|c|c|c|c|c|}
\hline Patients' pain and Anxiety & & SD & Mean & $\mathrm{N}$ & $\mathrm{P}$ (Spearman) & & \multicolumn{2}{|c|}{$\mathrm{R}$ (spearman) } \\
\hline Patient's pain & & 2.49 & 2.14 & 61 & & & & \\
\hline \multirow{2}{*}{ Patient's anxiety } & $0.355^{\mathrm{a}}$ & 10.32 & 41.81 & 61 & State anxiety & \multirow{2}{*}{$0.628^{b}$} & $0.005^{\mathrm{c}}$ & \multirow{2}{*}{$0.000^{\mathrm{d}}$} \\
\hline & $0.286^{\mathrm{a}}$ & 7.70 & 41.42 & 61 & Trait anxiety & & $0.025^{\mathrm{c}}$ & \\
\hline
\end{tabular}

\section{Discussion}

The aim of this study was to determine the correlation between pre-cystoscopy's anxieties with post-cystoscopy's pain. results of this study showed that the correlation between pre- cystoscopy's state anxiety and post-cystoscopy's pain is significant and direct.

Cystoscopy is one of common process that urologists use it (Yoshimura, Wada, \& Kishimoto, 1999). One of the challenging concept in pre-operative caring is anxiety (Jawaid, Mushtaq, Mukhtar, \& Khan, 2007) Most of patients awaiting for elective surgery are anxious (Badner, Nielson, Munk, Kwiatkowska, \& Gelb, 1990). In This study, fifty percent of patients have moderate score of trait and state of anxiety that is similar to study of Jawaid et al. (Jawaid, Mushtaq, Mukhtar, \& Khan, 2007), that showed there was significant anxiety in patients before surgery.

Studies have shown significant pain and discomfort in patients because of cystoscopy (Burke, Shackley, \& O'reilly, 2002; Grossfeld et al., 2001), in several studies, relationship between pre-cystoscopy factors with cystoscopy pain have been assessed (Ozdemir, Altinova, Koyuncu, Serefoglu, \& Balbay, 2014).

In this study, the pre-cystoscopy's anxiety (state and trait anxiety) and post-cystoscopy's pain of patients were assessed. The results showed that there was significant correlation between pre-cystoscopy's anxiety and post-cystoscopy's pain. in the study of stein et al., there was significant correlation between women's pre-cystoscopy's anxiety and their pain that is similar to the results of present study but results of their study showed that men's pre-cystoscopy's anxiety had no correlation with cystoscopy's pain(20). The reason of their findings maybe was related to the race of the participants, because their participants were Blacks and other race, difference of races may lead to difference in results.

In current study the correlation between state anxiety and cystoscopy's pain was stronger than the correlation between trait anxiety and cystoscopy's pain. The reason for this findings maybe is because that state anxiety creates with some factors like Imagine about procedure, lack of information about it and factors related to hospital conditions and nursing condition (Salehi, Amini, Frizzy-Amiry, \& Pakpour, 2017) and it creates in the same moment. Those factors may lead to sense pain after cystoscopy. The results of this study is similar to study of Soomro et al., jowang king yu et al., and kasra et al., (Soomro, Nasir, \& Ather, 2011; Yeo, Cho, Oh, Park, \& Park, 2013; Kesari, Kovisman, Cytron, \& Benjamin, 2003). In these studies cystoscopy's pain has reduced by using several anxiety reducing methods like showing cystoscopy process with video projector to patients and listening to music during cystoscopy (Soomro, Nasir, \& Ather, 2011; Yeo, Cho, Oh, Park, \& Park, 2013; Kesari, Kovisman, Cytron, \& Benjamin, 2003)). These studies confirmed that by reducing the cystoscopy's state anxiety, the cystoscopy's pain can be reduce significantly.

Chiu et al., has studied about the stress management in patients who had prostate biopsy, in this study patient divided into two groups (case and control). Case group received intervention for reduce of stress at pre procedure, results of this study show reducing of patients anxiety and pain in case group after procedure (Chiu et al., 2016). Result of this study have confirmed this issue that by removing stress which is one of the factors contributing to pain, we can prevent of post - operative pain.

According to the mentioned studies and results of present study, state anxiety is major factor that increases patient's pain, so it is recommended that an anxiety reduction programs for patient undergoing cystoscopy should be set up. The future studies can include study that compares different types of interventions to reduce 
patient's anxiety. The Limitation of this study is related to selfn - reporting of anxiety and pain by means of patients because the VAS scale and spilberger questionnaire are self - reporting instruments. Low sample size was other limitation of this study, because the researchers' time had one year's permission for collecting data, they had to end the project just with 61 participants.

\section{Conclusion}

Results of this study showed that the correlation between pre-cystoscopy's anxiety and post-cystoscopy's pain was significant, and the state anxiety which occurs due to the process itself, had stronger correlation with cystoscopy's pain. Therefore by using anxiety reducing methods before cystoscopy the patient's pain can be prevent and reduce significantly. The medications that have harmful results for patients can be reduce to use too which can help patients and governments economy.

\section{Acknowledgement}

This work was supported by Deputy of research and technology of Zanjan University of Medical Science; we would like express our gratitude and thanks for participants and nurses that help us.

\section{Conflict of interests}

The authors declare that there is no conflict of interests regarding the publication of this paper.

\section{References}

Andaroodi, M., Mahoori, A., Abbasivash, R., Noroozinia, H., \& Heshmati, F. (2006). Evaluation of the effectiveness of lidocaine infusion in reduction of postoperative pain. Journal of Shahid Sadoughi University of Medical Sciences, 14(3), 25-30.

Badner, N. H., Nielson, W. R., Munk, S., Kwiatkowska, C., \& Gelb, A. W. (1990). Preoperative anxiety: Detection and contributing factors. Canadian Journal of Anaesthesia, 37(4), 444. https://doi.org/10.1007/BF03005624

Badner, N., Nielson, W., Munk, S., Kwiatkowska, C., \& Gelb, A. (1990). Preoperative anxiety: Detection and contributing factors. Can J Anaesth, 37, 444-7. https://doi.org/10.1007/BF03005624

Bassampour, S., Nikbakht Nasrabadi, A., Mehran, A., Poresmaeil, Z., \& Valiee, S. (2008). Effect of acupressure on patients' anxiety and vital sign before abdominal surgeries. Journal of Hayat, 14(2), 23-34.

Bijur, P., Silver, W., \& Gallagher, E. (2001). Reliability Of The Visual Analog Scale For Measurement Of Acute Pain. Academic Emergency Medicine, 8(12), 1153-7. https://doi.org/10.1111/j.1553-2712.2001.tb01132.x

Boker, A., Brownell, L., \& Donen, N. (2002). The amsterdam preoperative anxiety and information scale provides a simple and reliable measure of preoperative anxiety. Can $J$ Anaesth, 49, 792-8. https://doi.org/10.1007/BF03017410

Bonica, J. J. (1990). Postoperative pain. The Management of Pain, 461.

Burke, D., Shackley, D., \& O'reilly, P. (2002). The community-based morbidity of flexible cystoscopy. BJU International, 89(4), 347-9. https://doi.org/10.1046/j.1464-4096.2001.01899.x

Chiu et al. (2016). Effectiveness of stress management in patients undergoing transrectal ultrasound-guided biopsy of the prostate. Patient Preference and Adherence, 10, 147. https://doi.org/10.2147/PPA.S96991

Chung, Y. C., Hou, Y. C., \& Pan, A. H. (2004). Endoglin (CD105) expression in the development of haemorrhoids. European Journal of Clinical Investigation, 34(2), 107-12. https://doi.org/10.1111/j.1365-2362.2004.01305.x

Dabbagh et al. (2010). Frequency of postoperative pain and its associated factors in Taleghani hospital. Research in Medicine, 33(4), 265-9.

Fadaizadeh, I., Emami, H., \& Samii, K. (2009). Comparison of Visual Analogue Scale and Faces Rating Scale in Measuring Acute Postoperative Pain. Arch Iranian Med., 12(1), 73-5.

Gagner-Tjellesen, D., Yurkovich, E. E., \& Gragert, M. (2001). Use of music therapy and other ITNIs in acute care. Journal of Psychosocial Nursing and Mental Health Services, 39(10), 26-37.

Ganei, R., Rezai, K., \& Mohamady, R. (2013). The Relationship between Preoperative Anxiety and Postoperative Pain after Cesarean Section. The Iranian Journal of Obsterices, Gynecology and Infertility, 15(39), 16-22. 
Gift, A. G. (1989). Visual analogue scales: Measurement of subjective phenomena. Nursing Research, 38(5), 286-8. https://doi.org/10.1097/00006199-198909000-00006

Grossfeld et al. (2001). Evaluation of asymptomatic microscopic hematuria in adults: the American Urological Association best practice policy-part II: Patient evaluation, cytology, voided markers, imaging, cystoscopy, nephrology evaluation, and follow-up1. Urology, 504-10. https://doi.org/10.1016/S0090-4295(01)00920-7

Gunnarsdottir, T. J., \& Jonsdottir, H. (2007). Does the experimental design capture the effects of complementary therapy? A study using reflexology for patients undergoing coronary artery bypass graft surgery. Journal of Clinical Nursing, 16(4), 777-85. https://doi.org/10.1111/j.1365-2702.2006.01634.x

Hobson, J., Slade, P., Wrench, I., \& Power, L. (2006). Preoperative anxiety and postoperative satisfaction in women undergoing elective caesarean section. International Journal of Obstetric Anesthesia, 15(1), 18-23. https://doi.org/10.1016/j.ijoa.2005.05.008

Jawaid, M., Mushtaq, A., Mukhtar, S., \& Khan, Z. (2007). Preoperative anxiety before elective surgery. Neurosciences, $12(2), 145-8$.

Jellinghaus, W. (1979). Evaluation of bladder tumors by endoscopic procedures. Endoscopy, 11(04), $231-5$. https://doi.org/10.1055/s-0028-1098356

Kesari, D., Kovisman, V., Cytron, S., \& Benjamin, J. (2003). Effects on pain and anxiety of patients viewing their cystoscopy in addition to a detailed explanation: A controlled study. BJU International, 92(7), 751-2. https://doi.org/10.1046/j.1464-410X.2003.04477.x

Kim, W.-S., Byeon, G.-J., Song, B.-J., \& Lee, H. J. (2010). Availability of preoperative anxiety scale as a predictive factor for hemodynamic changes during induction of anesthesia. Korean Journal of Anesthesiology, 58(4), 328-33. https://doi.org/10.4097/kjae.2010.58.4.328

Mokhtari, Nj., Sirati, Nm., Sadeghi, Sm., Ghanbari, Z., Babatabar, Dh., \& Mahmoudi, H. (2010). Comparison Of Impact Of Foot Reflexology Massage And Bensone Relaxation On Severity Of Pain After Cesarean Section: A Randomized Trial.

Morgan, J., Roufeil, L., Kaushik, S., \& Bassett, M. (1998). Influence of coping style and precolonoscopy information on pain and anxiety of colonoscopy. Gastrointestinal Endoscopy, 48(2), 119-27. https://doi.org/10.1016/S0016-5107(98)70152-X

Mudgalkar, N., Bele, S. D., Valsangkar, S., Bodhare, T. N., \& Gorre, M. (2012). Utility of numerical and visual analog scales for evaluating the post-operative pain in rural patients. Indian Journal of Anaesthesia, 56(6), 553. https://doi.org/10.4103/0019-5049.104573

Nikbakht Nasrabadi, A. (1994). The effecacy of Quran recitation on abdominal post-surgery pain: Tarbiat Modares University.

Ozdemir, A. T., Altinova, S., Koyuncu, H., Serefoglu, E. C., \& Balbay, M. D. (2014). Factors predictive of pain during cystoscopy: A prospective study. Journal of Clinical and Analytical Medicine, 5(3), 186-90. https://doi.org/10.4328/JCAM.1268

Rabiee, M., \& Kazemi Malek Mahmodi, S. (2007). The effect of music on the rate of anxiety among hospitalized children. Journal of Gorgan University of Medical Sciences, 9(3), 59-64.

Salehi, H., Amini, A., Frizzy-Amiry, B., \& Pakpour, V. (2017). Evaluating the quality of sleep among nurses working at educational hospitals of Zanjan University of Medical Sciences and its related factors. Nurs Pract Today, 4(4), 164-9

Soomro, K. Q., Nasir, A. R., \& Ather, M. H. (2011). Impact of patient's self-viewing of flexible cystoscopy on pain using a visual analog scale in a randomized controlled trial. Urology, 77(1), 21-3. https://doi.org/10.1016/j.urology.2010.08.012

Stein, M., Lubetkin, D., Taub, H. C., Skinner, W. K., Haberman, J., \& Kreutzer, E. R. (1994). The effects of intraurethral lidocaine anesthetic and patient anxiety on pain perception during cystoscopy. The Journal of Urology, 151(6), 1518-21. https://doi.org/10.1016/S0022-5347(17)35290-4

Tiedeman, M. E., \& Clatworthy, S. (1990). Anxiety responses of 5-to 11-year-old children during and after hospitalization. Journal of Pediatric Nursing: Nursing Care of Children and Families, 5(5), 334-43. 
Watt-Watson, J., Stevens, B., Garfinkel, P., Streiner, D., \& Gallop, R. (2001). Relationship between nurses’ pain knowledge and pain management outcomes for their postoperative cardiac patients. Journal of Advanced Nursing, 36(4), 535-45. https://doi.org/10.1046/j.1365-2648.2001.02006.x

Yeo, J. K., Cho, D. Y., Oh, M. M., Park, S. S., \& Park, M. G. (2013). Listening to music during cystoscopy decreases anxiety, pain, and dissatisfaction in patients: A pilot randomized controlled trial. Journal of Endourology, 27(4), 459-62. https://doi.org/10.1089/end.2012.0222

Yoshimura, R., Wada, S., \& Kishimoto, T. (1999). Why the flexible cystoscope has not yet been widely introduced? A questionnaire to Japanese urologists. International Journal of Urology, 6(11), 549-61. https://doi.org/10.1046/j.1442-2042.1999.611112.x

Zakerimoghadam, M., Aliasgharpoor, M., Mehran, A., \& Mohammadi, S. (2010). Effect of patient education about pain control on patients' anxiety prior to abdominal surgery. Journal of Hayat, 15(4), 13-22.

\section{Copyrights}

Copyright for this article is retained by the author(s), with first publication rights granted to the journal.

This is an open-access article distributed under the terms and conditions of the Creative Commons Attribution license (http://creativecommons.org/licenses/by/4.0/). 